\title{
Construcciones discursivas en la nueva legislación de aguas en el Ecuador
}

\author{
Alex Zapatta \\ Universidad Central del Ecuador \\ alexzapatta@yahoo.com
}

RESUMEN

Este artículo hace una revisión a los contenidos más sobresalientes y polémicos del nuevo marco normativo de las aguas en el Ecuador, particularmente de la Ley Orgánica de Recursos Hídricos, Usos y Aprovechamiento del Agua — vigente desde la segunda mitad de 2014-, apoyándose en la categoría de «discurso del derecho» desarrollado por el jurista Óscar Correas e identificando tensiones entre las construcciones discursivas que le han dado forma. Se concluye que esta ley, que refleja la concepción política en torno a la gestión de las aguas por la «Revolución Ciudadana», da cuenta de la perspectiva de un sector que, desde el control vertical del aparataje estatal, alienta una modernización capitalista de la economía buscando sostener y ampliar el aprovechamiento rentista del agua.

Palabras clave: Ecuador, razonabilidad práctica, discurso del derecho, legislación de aguas, recursos hídricos. 


\section{Discursive constructions of the new water legislation in Ecuador}

\section{ABSTRACT}

Based on the concept of «law discourse content» developed by Óscar Correas, this article examines the more outstanding and controversial issues of the new water regulation framework in Ecuador, with emphasis on the «Ley Orgánica de Recursos Hídricos, Usos y Aprovechamiento del Agua», in force since second half 2014, and identifying the tensions between the discursive constructions that frame the new regulation. This leads us to the following conclusion: the law reveals a political conception on water management by the «Citizen Revolution» which, from the vertical control of the state apparatus, encourages a capitalist modernization of the economy seeking to support and expand a rentier use of water.

Keywords: Ecuador, practical reasonableness, law discourse, water legislation, water resources. 


\section{INTRODUCCIÓN}

A inicios de la década de 1980, tras un decenio de gobiernos de corte dictatorial, el entonces denominado «retorno a la democracia» fue acompasado por políticas neoliberales, aplicadas con distintos matices hasta mediados de los años 2000.

A inicios de 2006, tras un largo período de movilizaciones sociales que dieron cuenta incluso de la caída de tres gobiernos empecinados en aplicar políticas del Fondo Monetario Internacional, el Banco Mundial y el Banco Interamericano de Desarrollo, y con el fracaso de las negociaciones del Tratado de Libre Comercio entre el Ecuador y Estados Unidos, se cerró el ciclo de aplicación más o menos ortodoxa de políticas neoliberales o de ajuste estructural.

En ese momento, el espíritu refundacional estaba extendido en diversos sectores de la sociedad ecuatoriana. La idea de que era necesaria una Asamblea Constituyente flotaba en el ambiente político. Es en ese contexto cuando emerge políticamente Rafael Correa y su proyecto de «Revolución Ciudadana» ${ }^{1}$.

En abril de 2007, una consulta popular favoreció la convocatoria a una Asamblea Nacional Constituyente, de cuyo trabajo el fruto central será el texto de la Constitución del año 2008.

Esta Constitución, con toda seguridad la carta política que más tratamiento da al tema de las aguas, tiene en su artículo 318 el conjunto de lineamientos más destacados en torno a la gestión del agua ${ }^{2}$ :

Art. 318.- El agua es patrimonio nacional estratégico de uso público, dominio inalienable e imprescriptible del Estado, y constituye un elemento vital para la naturaleza y para la existencia de los seres humanos. Se prohíbe toda forma de privatización del agua.

Correa ganó las elecciones por primera vez en el año 2006. Inició su presidencia en el año 2007.

2 Veinte artículos de la Constitución y tres de sus disposiciones transitorias abordan de una u otra manera la cuestión del agua. 
La gestión del agua será exclusivamente pública o comunitaria. El servicio público de saneamiento, el abastecimiento de agua potable y el riego serán prestados únicamente por personas jurídicas estatales o comunitarias.

El Estado fortalecerá la gestión y funcionamiento de las iniciativas comunitarias en torno a la gestión del agua y la prestación de los servicios públicos, mediante el incentivo de alianzas entre lo público y comunitario para la prestación de servicios.

El Estado, a través de la autoridad única del agua, será el responsable directo de la planificación y gestión de los recursos hídricos que se destinarán a consumo humano, riego que garantice la soberanía alimentaria, caudal ecológico y actividades productivas, en este orden de prelación. Se requerirá autorización del Estado para el aprovechamiento del agua con fines productivos por parte de los sectores público, privado y de la economía popular y solidaria, de acuerdo con la ley.

Tal carta política, en su primera disposición transitoria, estableció el plazo de 360 días para que el órgano legislativo apruebe una ley que regule los recursos hídricos, usos y aprovechamiento del agua.

Esta disposición, sin embargo, no pudo ser implementada en el plazo señalado. Hicieron falta cinco años para que esa ley fuese aprobada, cinco años en los que se elaboraron y reelaboraron dieciocho versiones oficiales de proyectos de ley, pero también cinco años que fueron dando cuenta de las disputas en torno al sentido de las políticas y su expresión normativa y de los complejos cambios en el contexto político del país.

Entre fines de 2008 y mediados de 2009, período en el que el Ecuador debatió los contenidos de la nueva legislación de aguas, se desarrolló un proceso marcado por disputas en torno a los sentidos y alcances de los textos, por tensiones y movilizaciones sociales, pero también por decisiones políticas del Estado que fueron estableciendo una clara direccionalidad en la política de las aguas ${ }^{3}$.

En el campo de las organizaciones sociales agrarias y de sus aliados, hubo iniciativas y empuje movilizador que cuestionaban el sentido y contenidos que el gobierno daba a las políticas del agua y a su proyecto de nueva legislación.

En mayo de 2010 el proyecto de Ley de Recursos Hídricos estuvo a punto de ser aprobado en segundo debate por la Asamblea Nacional (el órgano legislativo del Ecuador); sin embargo, la presión generada por una importante movilización indígena y campesina liderada por la Confederación de Nacionalidades Indígenas

Al respecto pueden consultarse varios artículos publicados por el Foro de los Recursos Hídricos (www.camaren.org). 
del Ecuador (CONAIE) bloqueó su aprobación. La justificación que el entonces presidente de la Asamblea Nacional encontró para suspender la votación fue que, antes de que la ley fuese aprobada, primero debía procederse con la consulta prelegislativa a los pueblos indígenas ${ }^{4,5}$.

A mediados de 2014, tras la consulta prelegislativa — cuya legitimidad quedó en entredicho- - se aprobó la Ley Orgánica de Recursos Hídricos, Usos y Aprovechamiento del Agua (LORHUAA) ${ }^{6,7}$.

Con ello, a la vez que entró en vigencia esa ley, quedó derogada la Ley de Aguas de 1972, que por 42 años jugó un papel importante en la gestión pública de los recursos hídricos en el Ecuador.

La entrada en vigencia de esta nueva ley cerró un largo ciclo de discusiones en torno a la necesidad de que el país cuente con una nueva legislación de aguas, ciclo que se extendió por veinte años, pues desde el año 1994 — cuando en el marco de políticas de ajuste estructural y a través de la Ley de Desarrollo Agrario fueron introducidas importantes modificaciones al marco normativo de las aguas-, el país debatió largamente en torno a la necesidad de contar con un renovado marco legal de las aguas.

En efecto, se cerró un ciclo pero comenzó otro. Tanto el movimiento indígena como muchas de las organizaciones de usuarios de sistemas de agua de gestión colectiva han cuestionado los contenidos de la ley y su reglamento, poniendo en duda además la constitucionalidad de varios de sus artículos ${ }^{8}$.

$4 \quad$ El derecho a la consulta previa está reconocido por la Constitución en su artículo 57, numeral 7.

5 Aunque las organizaciones comunitarias fueron convocadas a la consulta prelegislativa tomando como referente la versión diecisiete del proyecto de ley (que fue la que estuvo a punto de ser aprobada en mayo de 2010), el texto que sirvió de base para la aprobación de la ley fue en realidad una versión dieciocho (que jamás fue públicamente conocida, y menos debatida).

6 Paradójicamente, los temas de la consulta, los sujetos de la consulta y el procesamiento de sus resultados estuvieron definidos y controlados por la Asamblea Nacional (el órgano legislativo), cuyos miembros mayoritariamente eran integrantes de «Alianza País» el movimiento político que lidera el presidente Correa. Súmese a lo señalado que los resultados de la consulta no son considerados como vinculantes.

7 Vigente desde su publicación en el segundo suplemento del Registro Oficial, número 305, del día miércoles 6 de agosto del año 2014.

8 Ante la Corte Constitucional se presentaron dos demandas de inconstitucionalidad: una por la Confederación de Nacionalidades del Ecuador (CONAIE), y otra planteada por la Federación de Pueblos Kichwas del Ecuador (ECUARUNARI). Ambas demandas cuestionan la forma y el fondo de la Ley Orgánica de Recursos Hídricos. En cuanto a los aspectos de fondo, se cuestiona el desconocimiento de los tratados internacionales ratificados por el Ecuador relativos al reconocimiento de los derechos colectivos de los pueblos indígenas; la regresividad del 
En las líneas que siguen, se revisa el presupuesto teórico metodológico a partir del cual se organizó el análisis de la Ley de Recursos Hídricos.

\section{CONSIDERACIONES TEÓRICO METODOLÓGICAS}

Precisamente, la redacción de este artículo se inserta en el nuevo ciclo de discusiones en torno al marco a las políticas, normativa e institucionalidad de las aguas que se abre con la entrada en vigencia de la Ley de Recursos Hídricos.

Ante la serie de voces que han advertido que esa ley es una suerte de punta de lanza de la estructuración de un entramado normativo e institucional que se orienta a favorecer a que el Estado, embarcado en un gran proyecto modernizador con sesgos extractivistas, afirme un control vertical y excluyente de las aguas, este artículo se redactó con el interés de colocar una reflexión crítica al contenido de ese cuerpo normativo, a las construcciones discursivas que le han dado forma, así como a las racionalidades que se expresan en dicha ley.

Para organizar el análisis e identificar los contenidos y discursos de la nueva legislación de aguas del Ecuador se han tenido presentes aportes del «derecho crítico latinoamericano», en tanto que para indagar sobre las racionalidades de ese marco jurídico se recogen aportes de aquellas perspectivas ubicadas en lo que genéricamente se conoce como «teorías de la argumentación jurídica». Para ello, conviene que, aunque muy brevemente, se precise el alcance de esas dos perspectivas del pensamiento jurídico.

En cuanto al derecho crítico latinoamericano, Antonio Wolkmer, uno de sus expositores, resume tal perspectiva en los siguientes términos:

Se puede conceptualizar la «teoría jurídica crítica», por un lado, como la formulación teórico-práctica que se revela bajo la forma del ejercicio reflexivo capaz de cuestionar y de romper con aquello que se encuentra disciplinariamente ordenado y oficialmente consagrado (en el conocimiento, en el discurso y en el comportamiento) en determinada formación social; por el otro, como la posibilidad de concebir y revivir otras formas diferenciadas, no represivas y emancipadoras, de práctica jurídica (Wolkmer, 2003, p. 33).

derecho al agua para los pueblos y nacionalidades indígenas, y la restricción de los derechos al territorio, a la identidad cultural y tradiciones ancestrales, y a la soberanía alimentaria. 
En cuanto a las teorías de la argumentación jurídica ${ }^{9}$, Manuel Atienza, uno de sus más reconocidos expositores, las describe en los siguientes términos:

La teoría o teorías de la argumentación jurídica tiene como objeto de reflexión, obviamente, las argumentaciones que tienen lugar en contextos jurídicos. En principio pueden distinguirse tres distintos campos de lo jurídico en que se efectúan argumentaciones. El primero de ellos es el de la producción o establecimiento de normas jurídicas [...].

Un segundo campo en que se efectúan argumentos jurídicos es el de la aplicación de normas jurídicas a la resolución de casos [...].

Finalmente, el tercer ámbito en que tienen lugar argumentos jurídicos es el de la dogmática jurídica [...]. (Atienza, 2005, pp. 1 y 2).

Agrega Atienza:

La teoría de la argumentación jurídica tendría que comprometerse con una concepción —una ideología política y moral- más crítica con respecto al derecho de los estados democráticos, lo que, por otro lado, podría suponer también adoptar una perspectiva más realista (2005., p. 218).

En la aproximación a las construcciones discursivas que se expresan en la ley, se ha recurrido a los aportes de uno de los pensadores más representativos de la corriente del derecho crítico latinoamericano: Óscar Correas, quien ha señalado que «la crítica del derecho es, finalmente, un análisis del discurso del derecho» (Correas, 2010, p. 308).

El pensador argentino-mexicano advierte sobre la necesidad de diferenciar, en el discurso del derecho, un discurso específicamente preceptivo, de «sentido deóntico» que prescribe conductas, el deber ser, a través de normas que prohíben, obligan o permiten, y un discurso ideológico que marca el «sentido político» de una norma o una ley, discursos ambos que coexisten en el mismo texto. En palabras de Correas:

El sentido deóntico del discurso del derecho está constituido por lo que los juristas llaman «normas jurídicas». El discurso del derecho transmite la especial ideología de que alguien debe hacer algo [...]. El discurso del derecho no solo contiene normas. Pero contiene normas, y en ellas consiste su sentido deóntico. [...].

9 Perspectiva teórica que se podría ubicar en la tendencia iusfilosófica identificada como postpositivismo. 
Todo otro sentido o ideología que no sea la pura norma, es lo que llamaremos sentido ideológico del derecho. Es decir, en el discurso del derecho existen, además de normas, muchos otros mensajes [...] (Correas, 2010 [2004], pp. 58 y 71).

Desde una perspectiva próxima a la argumentación jurídica, se reconoce que en la teoría y práctica legislativa convergen diversas racionalidades, que tiene por eje una racionalidad práctica, que abarca o se complementa con una racionalidad política, y una racionalidad propiamente jurídica. El énfasis y peso que se supone tiene o debe tener una u otra de esas racionalidades es objeto de un importante debate teórico en el ámbito de la teoría jurídica, y a su interior, en la teoría de la legislación.

García Amado aporta a una reflexión sobre la teoría general de la legislación desde una concepción basada en la recuperación de la categoría de la «razón práctica»:

Cuando hablamos de razón o racionalidad práctica, nos referimos a los criterios mediante los que cabe, si es que cabe, la justificación intersubjetivamente aceptable de opciones relativas a acciones o cursos de acción. Hablamos, es obvio, de las reglas de la razón que, si es que caben tales, pueden y deben regir los juicios y valoraciones entre alternativas comportamentales diferentes (por ejemplo entre dar a la ley uno u otro contenido cuando se es legislador) (García Amado, 2003, p. 4).

Agrega García Amado que la teoría de la legislación tendría la misión de explicar las consecuencias y aplicaciones concretas que de la racionalidad práctica se derivan para la actividad legislativa, con el fin de que podamos considerar racionales tanto esa actividad como su resultado.

El tratadista español sostiene que una actividad que tenga por objeto una generación legislativa de carácter democrático implica la plasmación práctica y procedimental de una cierta racionalidad que tiene su eje en el respeto de los interlocutores y de su igualdad, lo que él denomina «razón de consistencia». Al mismo tiempo, reivindicando a Habermas, García Amado propone recuperar para la actividad legislativa la ética discursiva como búsqueda de entendimiento, como consenso en torno a la pretensión de validez (ya sean pretensiones de verdad, de rectitud o de veracidad). Si este consenso no surge de modo inmediato, es necesario reconstruirlo en un discurso, en un proceso argumentativo del que solo saldrá un acuerdo racional cuando esté presidido por el respeto de las reglas, que no son otras que las «reglas de la argumentación racional» (García Amado, 2003, pp. 15 y 18). 
A partir de los presupuestos referidos, se organizó la revisión de la nueva legislación de aguas en el Ecuador. Para ello, se siguió el siguiente itinerario metodológico: (i) se identificaron aquellos segmentos de la ley que han tenido mayor connotación en el debate político y jurídico en este país andino; (ii) en los segmentos identificados, se analizaron las tensiones discursivas, y finalmente, (iii) se trabajó en caracterizar las racionalidades y construcciones discursivas que fueron moldeando los contenidos de la ley.

En lo que sigue, se sintetiza lo medular de la referida revisión.

\section{LOS CONTENIDOS Y DISCURSOS DE LA NUEVA LEGISLACIÓN DE AGUAS}

\section{Los nuevos roles del Estado}

En tanto que la caracterización jurídica de las aguas fue la de «bienes nacionales de uso público», el binomio normativo integrado por la Ley de Creación del Instituto Ecuatoriano de Recursos Hidráulicos (INERHI) de 1966 y la Ley de Aguas de 1972 institucionalizó un rol para el Estado en la gestión de las aguas: el de regulador de la gestión multisectorial de los recursos hídricos, de los derechos de uso y aprovechamiento del agua y de la prestación de los servicios públicos que dependen del agua.

La Constitución de 2008 da una nueva caracterización jurídica a las aguas: la de "patrimonio nacional estratégico», tal es el reconocimiento del artículo 12 de la carta política del país. ¿Qué significa aquello de que el agua es parte de los denominados sectores estratégicos? La respuesta está en el artículo 313 de la misma Constitución:

Art. 313.- El Estado se reserva el derecho de administrar, regular, controlar y gestionar los sectores estratégicos, de conformidad con los principios de sostenibilidad ambiental, precaución, prevención y eficiencia.

Los sectores estratégicos, de decisión y control exclusivo del Estado son aquellos que por su trascendencia y magnitud tienen decisiva influencia económica, social, política o ambiental, y deberán orientarse al pleno desarrollo de los derechos y al interés social.

Se consideran sectores estratégicos la energía en todas sus formas, las telecomunicaciones, los recursos naturales no renovables, el transporte y la refinación de hidrocarburos, la biodiversidad y el patrimonio genético, el espectro radioeléctrico, el agua, y los demás que determine la ley [los subrayados corresponden al autor del artículo]. 
Aunque al definir la condición del agua como parte de los sectores estratégicos la LORHUAA reproduce en buena medida el contenido de la Constitución, la parte normativa y preceptiva de la ley establece una marcada potestad discrecional de la institucionalidad estatal de las aguas, un desbordante incremento las regulaciones estatales a la gestión del agua, sumando además un nuevo rol para el Estado respecto de la gestión de las aguas: el de interventor.

A propósito de lo antes señalado, y en abierta contraposición a lo definido en el artículo 318 de la Constitución, la ley avala la posibilidad de que las organizaciones sociales vinculadas con la gestión colectiva del agua - que en la ley tiene la forma de «juntas de agua»— puedan ser intervenidas por el Estado cuando «incumplan las normas técnicas» ${ }^{10}$.

El reglamento a la ley - que fue elaborado por la Secretaría Nacional del Agua (Senagua) - va más lejos ${ }^{11}$. Con una redacción que releja un inusual entusiasmo, desarrolla y amplía las posibilidades de intervención a las organizaciones que gestionan colectivamente sistemas de agua (por ejemplo, cuando estas incumplan con los «planes de mejora» o cuando infrinjan «regulaciones técnicas») ${ }^{12}$.

La ley atribuye a la autoridad única del agua ${ }^{13}$ —es decir a la Senagua—, así como a la Agencia de Regulación y Control del Agua (ARCA), una marcada potestad discrecional para emitir una normativa secundaria - de carácter «procedimental»o «técnico»—e en relación con la gestión del agua.

Se advierte un exceso de regulaciones normativas para asegurar el deseado control exclusivo, al parecer no frente a los grupos que históricamente han venido controlando las aguas en los distintos ámbitos territoriales, sino frente a los ineficientes sistemas comunitarios de agua, cuestión que, desde luego, forma parte del acervo ideológico de la ley ${ }^{14}$.

Para que tenga justificación social y jurídica el desdén e intento de subordinación de las organizaciones que gestionan colectivamente los sistemas de agua,

Tal posibilidad está desarrollada en el artículo 51 de la LORHUAA.

El Reglamento a la Ley Orgánica de Recursos Hídricos fue aprobado mediante decreto ejecutivo 650 y se publicó en el primer suplemento del Registro Oficial 483, del día 20 de abril de 2015. El reglamento fue modificado parcialmente mediante decreto ejecutivo 740, del 3 de agosto de 2015.

Allí está el contenido de los artículos 47 y 51 del reglamento.

En el texto constitucional, al hacer referencia a la autoridad única del agua, se utilizan minúsculas; en la ley y en la normativa generada por la Senagua, generalmente se utilizan mayúsculas. En este artículo, cuando la cita es textual, se transcribe con la ortografía original.

El más serio y documentado análisis e información respecto del reparto social de las aguas en irrigación se encuentra desarrollado en el trabajo de Antonio Gaybor (2008): «El despojo del agua y la necesidad de una transformación urgente». Foro de los Recursos Hídricos. 
se ha sacralizado en la Ley de Recursos Hídricos la noción de lo técnico, cuestión que queda bajo el monopolio del Estado y sujeta al criterio de sus funcionarios. En la ley, lo técnico es lo que prohíbe o permite, el todo y la nada, lo importante y lo banal, lo que está sobre el bien y el mal ${ }^{15}$.

Ciertamente, en la lógica de la ley, lo técnico es una representación de un imaginario de matriz colonial que plantea la superioridad de los saberes de los funcionarios estatales sobre los saberes populares, campesinos e indígenas, la superioridad del conocimiento ingenieril sobre el de las prácticas tradicionales y ancestrales, la necesidad de asegurar la eficiencia allí donde supuestamente ha sido reinado de la ineficiencia; en fin, garantizar el dominio de lo moderno sobre lo tradicional y arcaico.

Por otro lado, tanto en la ley como especialmente en su reglamento se detallan minuciosamente las obligaciones, exigencias y requisitos que deben cumplir las organizaciones que gestionan colectivamente el agua para no perder su personería jurídica o quedarse sin la asignación estatal de derechos de agua. Sin embargo, en contrapartida, más allá de enunciados generales, ni la ley $-\mathrm{y}$ mucho menos el reglamento o los instructivos generados por la Senagua o la ARCA - precisan las responsabilidades y obligaciones que tendría el Estado - en sus diferentes niveles de gobierno - para contribuir a que las organizaciones de usuarios de sistemas de agua cuenten con las mínimas condiciones para volverse «eficientes».

\section{La gestión de los recursos hídricos}

Es del todo evidente que quienes redactaron la versión final de la Ley de Recursos Hídricos querían asegurar para el Estado el control de cualquier espacio de construcción de política y estrategias en torno a los recursos hídricos y a la gestión del agua ${ }^{16}$.

El otro aspecto que se evidencia en el contenido de la ley es el poco interés de sus redactores por recuperar e integrar en elementos que se desprenden de un sinnúmero de experiencias que se han dado en el Ecuador y en toda América Latina en torno a la planificación de los recursos hídricos y la gestión de cuencas,

\footnotetext{
15 En la ley hay veintisiete alusiones a lo técnico.

16 Aunque se trata de contextos muy distintos, es difícil no caer en la tentación de establecer una relación con algunos rasgos de las sociedades hidráulicas a las que se refiere Wittfoguel en su trabajo sobre el despotismo oriental (1966 [1963]).
} 
con distintos grados de acierto o éxito, es verdad, pero al fin y al cabo llenas de enseñanzas ${ }^{17}$.

Pero no solo eso: aportes de especialistas - en algún caso incluso contratado por la misma Senagua - para contribuir a incorporar un enfoque de gestión integrada de recursos hídricos a la ley no fueron debidamente considerados ${ }^{18}$.

De hecho, aunque en la ley mucho se hace referencia a la «gestión integral e integrada» de los recursos hídricos, tal concepción no está refrendada prescriptivamente ${ }^{19}$.

En la ley existen dos artículos: el 8 y el 34, que literalmente tienen el mismo contenido - es decir, el uno duplica el contenido del otro-y que llevan por título «Gestión integrada de los recursos hídricos»o «Gestión integrada e integral de los recursos hídricos». Son ejemplo de un enfoque limitado de gestión integrada de recursos hídricos (GIRH), pues no solo comienzan por colocar a la autoridad única del agua como «responsable de la gestión integrada e integral de los recursos hídricos», sino que hacen abstracción de un debate importante dado en toda América Latina en torno a si solo la cuenca hidrográfica puede seguir siendo considerada como unidad de gestión y planificación de los recursos hídricos.

Con relación a los organismos de cuenca hidrográfica, que la ley formaliza como «consejos de cuenca», están definidos por el artículo 25 de la ley, donde se precisa que el Consejo de Cuenca Hidrográfica es «el órgano colegiado de carácter consultivo, liderado por la Autoridad Única del Agua e integrado por los representantes electos de las organizaciones de usuarios, con la finalidad de participar en la formulación, planificación, evaluación y control de los recursos hídricos en la respectiva cuenca».

El artículo 26 del reglamento precisa que habrá consejos de cuenca en las unidades de planificación hidrográfica local y en el ámbito de las demarcaciones hidrográficas, espacios que serán establecidos «de acuerdo a la planificación que determina la Autoridad Única del Agua».

El artículo 27 del reglamento establece la forma como deben conformarse los consejos de cuenca, equiparando al representante de los sectores productivos

17 Solo por citar algunos ejemplos, en el Ecuador, entre otras, han tenido relevancia las experiencias del Consejo de la Cuenca del Paute, de la Mancomunidad para la Gestión de la Cuenca Alta del Río Jubones, del Consorcio Carchi para el Manejo de la Cuenca del río El Ángel y, más recientemente, del Comité de Gestión de la Subcuenca del Río Chambo.

18 En el primer semestre del año 2010, la Senagua contrató a un reconocido experto en los temas de gestión integrada de los recursos hídricos: Axel Dourojeanni, ex funcionario de la CEPAL.

Vg. artículos 4.g, 8, 20.4, 34, 42, y 65 de la ley. 
con los representantes de los sistemas de agua potable y de riego, excluyendo a las comunidades campesinas e indígenas y colocando a los representantes de la Senagua como coordinadores de tales consejos.

El énfasis de la ley en el sentido de que la autoridad única del agua — es decir, la Senagua - está el vértice superior de los consejos de cuenca da a la ley una cierta condición de cuerpo legitimador de esquemas verticales en la gestión de los recursos hídricos, dejando formalmente por fuera la posibilidad de que los gobiernos municipales o provinciales, de forma asociada o mancomunada, $\mathrm{o}$ acaso a través de plataformas público-comunitarias, puedan asumir tal responsabilidad.

Es difícil entender por fuera de las lógicas de control vertical el hecho de que las normas revisadas establezcan con exclusividad dos nociones espaciales en las que se pueden conformar organismos de cuenca - en extremo tecnocráticas-, dejando por fuera otras nociones espaciales más próximas a las comunidades, poblaciones y organizaciones vinculadas con la gestión del agua.

La perspectiva ideológica con la que se ha formulado la ley puede ser identificada no solo por la legitimación de políticas verticales, sino además por la ruidosa exclusión de las organizaciones indígenas y campesinas ${ }^{20}$, que no fueron consideradas en la composición de los organismos de cuenca. Pero además, ¿cómo se podría explicar, si no es por una concepción verticalista, el que se quiera normar en una ley la composición de los organismos de cuenca, detallando quiénes pueden o no formar parte de tales organismos?

\section{La planificación de los recursos hídricos}

En un momento en que el Ecuador había conseguido reinstitucionalizar la planificación de la política y la gestión pública, se desaprovechó la oportunidad de trabajar en la formulación de un plan nacional de los recursos hídricos que recogiera las experiencias de planificación acumuladas por los distintos niveles de gobiernos autónomos descentralizados, así como las experiencias de manejo de los recursos hídricos y de usos del agua de ese universo de organizaciones sociales y comunitarias regadas por todo el país. La formulación del denominado Plan Nacional de Gestión Integrada e Integral de los Recursos Hídricos de las Cuencas y Microcuencas Hidrográficas del Ecuador básicamente fue el resultado de un

20 Parece que quienes redactaron la ley, deliberadamente o por desconocimiento, pasaron por alto que en la casi totalidad de nacientes de las aguas están asentados pueblos indígenas, algunos de cuyos integrantes incluso, en un afán propagandístico, fueron reconocidos por la Senagua como «guardianes del agua». 
proceso de consultorías en el que participaron empresas extranjeras, planificación en la cual a los gobiernos autónomos descentralizados y a las organizaciones de usuarios les correspondió ser suministradores o validadores de información.

En la Ley de Recursos Hídricos se estableció que corresponde a la Senagua la formulación del Plan Nacional de Recursos Hídricos y los planes de gestión integral de los recursos hídricos por cuenca hidrográfica (artículo 30) y su ejecución (artículo 28), a la vez que se definió cuáles son los contenidos que debe contemplar dicha planificación (artículo 29), disposiciones que, en conjunto, claramente reflejan un enfoque de planificación centralista y excluyente.

Interesa destacar el contenido del último párrafo del artículo 28 de la ley:

Las autorizaciones existentes de uso y aprovechamiento del agua deberán ser compatibles con lo establecido en los planes de gestión integral de recursos hídricos por cuenca, caso contrario, deberán revisarse en armonía con el Plan Nacional de Recursos Hídricos, de conformidad a lo previsto en el reglamento a esta ley.

Tal formulación normativa, que con respecto a los derechos de agua entraña cierta condición de incertidumbre, a la vez que remueve el principio de «seguridad jurídica», tan reivindicado por la cultura jurídica de tradición liberal. En perspectiva, plantea un desafío a las organizaciones que gestionan colectivamente sistemas de agua. Si se tiene en cuenta que estas han obtenido del Estado el reconocimiento de derechos de agua en sus territorios solo tras denodados, largos $\mathrm{y}$ - con frecuencia - costosos esfuerzos, habrá que preguntarse qué sucedería si mañana a algún tecnócrata se le ocurriese decir que es mejor destinar esa agua para otro uso más acorde con el Plan Hídrico, con el cambio de matriz productiva o con una nueva versión del Plan Nacional de Desarrollo...

\section{La participación del sector privado en los servicios públicos que aprovechan el agua}

«Se prohíbe toda forma de privatización del agua». Tal es el señalamiento del artículo 6 de la ley, artículo que guarda armonía con lo dispuesto en el artículo 318 de la Constitución.

Sin embargo, en una clara demostración de malabarismo jurídico, en el siguiente artículo de la misma ley se plantean excepciones a la antes referida prohibición. 
Efectivamente, el contenido del artículo 7 de la ley establece que en la prestación de los servicios públicos del agua, bajo determinadas circunstancias, «excepcionalmente podrán participar la iniciativa privada y la economía popular», cuestión ampliada en el artículo 6 del reglamento. Tales disposiciones no solo se pasan por «encima» o por «debajo» del contenido del artículo 318 de la Constitución - según se quiera ver-, sino que ignoran el mandato contenido en la transitoria Vigesimosexta de la Constitución, cuyo texto es el siguiente ${ }^{21}$ :

[TRANSITORIA] VIGESIMOSEXTA.- En el plazo de trescientos sesenta días a partir de la entrada en vigencia de esta Constitución, las delegaciones de servicios públicos en agua y saneamiento realizadas a empresas privadas serán auditadas financiera, jurídica, ambiental y socialmente.

El Estado definirá la vigencia, renegociación y, en su caso, la terminación de los contratos de delegación, de acuerdo con lo establecido en esta Constitución y en los resultados de las auditorías.

Se condonan a las usuarias y usuarios en extrema pobreza las deudas de agua de consumo humano que hayan contraído hasta la entrada en vigencia de esta Constitución.

\section{La distribución social del agua}

El artículo 129 de la Ley de Recursos Hídricos define el acaparamiento de las aguas como «la disposición o la retención, por cualquier medio, de un caudal o caudales de agua para uso y aprovechamiento productivo en cantidades mayores a las necesarias, que perjudique a terceros». Seguidamente establece que «la Autoridad Única del Agua, con base en un estudio técnico que garantice la eficiencia en el uso y manejo, determinará en cada caso la existencia o no de acaparamiento».

¿Es posible - y creíble - que el acaparamiento de las aguas se evalúe a través estudios que garanticen la «eficiencia en el uso y manejo del agua»? Parece que lo más lógico es suponer que la evaluación del acaparamiento del agua implicaría el desarrollo de estudios que relacionen la distribución del agua con la propiedad agraria, con los usos del agua y los beneficios que se deriven de tales usos.

En la ley no se fijan sanciones para los acaparadores del agua. A propósito de este aspecto, si, siguiendo a Correas, asumimos que el derecho es un «sistema de

21 En mayo de 2010 este fue uno de los aspectos considerados «críticos» en la puja entre el movimiento indígena y el gobierno en torno a los contenidos de la Ley de Recursos Hídricos. 
discursos», como todo discurso este debe ser analizado no solo por lo que dice sino también por lo que no dice.

El artículo 130 de la ley hace referencia a la «redistribución y reasignación del agua». Aunque de manera general se pudiera considerar que dicho artículo está redactado de una forma tal que pudiera generar consensos, no deja de llamar la atención — nuevamente - que los criterios reasignación definidos en esa norma sean «técnicos, de eficiencia, sociales, económicos, ambientales y del respectivo consejo de cuenca».

Para evaluar la relación - de cercanía o distancia - entre la ley comentada y la Constitución, debe recordarse que, en el «momento político refundacional» al que se hizo referencia al inicio de este artículo, el acaparamiento de las aguas era un tema de preocupación de la Asamblea Constituyente. Tanto es así que la Constitución, en su transitoria Vigésimo Séptima, estableció el siguiente mandato:

[TRANSITORIA] VIGESIMOSÉPTIMA.- El Ejecutivo, en el plazo de dos años desde la entrada en vigencia de esta Constitución, revisará la situación de acceso al agua de riego con el fin de reorganizar el otorgamiento de las concesiones, evitar el abuso y las inequidades en las tarifas de uso, y garantizar una distribución y acceso más equitativo, en particular a los pequeños y medianos productores agropecuarios.

\section{La participación social}

La demanda de democratización del Estado que se hizo latente en el proceso constituyente tiene una de sus expresiones más tangibles en la exigencia de una amplia y auténtica participación social en la formulación e implementación de políticas públicas.

La Constitución recoge tal demanda en varios artículos. En el párrafo final de uno de ellos, el 85, se dice lo siguiente:

En la formulación, ejecución, evaluación y control de las políticas públicas y servicios públicos se garantizará la participación de las personas, comunidades, pueblos y nacionalidades.

Por supuesto, en varios de sus artículos la LORHUAA hace referencia a los temas de participación ${ }^{22}$. El problema radica en cómo son abordados los temas de participación en la norma analizada. Si se examinan los temas de participación a

\footnotetext{
22 Más de treinta artículos de la ley hacen referencia a la participación social.
} 
la luz de algunas de las disposiciones constitucionales, como la antes citada, la conclusión inevitable es que tales temas son desnaturalizados, despojados de todo contenido trascendente, para volverse formalidad insubstancial o requerimiento funcional a la lógica estatal.

En la ley, los temas de participación se reducen a formalidad declarativa sin carácter preceptivo alguno, a mecanismo de legitimación social de la política estatal, o a forma de homologación como responsabilidad que las comunidades $\mathrm{u}$ organizaciones de usuarios deben compartir con el Estado. Un detalle de lo señalado puede verse en el Anexo 1.

El tratamiento de la ley a las organizaciones de usuarios de los sistemas de agua de gestión colectiva

No obstante varias alusiones a las alianzas público comunitarias, la ley establece un esquema de relación subordinada y condicionada de las organizaciones de usuarios del agua a las lógicas del Estado.

A pesar de que en su artículo 49 formalmente se reconoce a las organizaciones que forman sistemas comunitarios de agua «autonomía administrativa, financiera y de gestión», la ley establece un marco de autonomía limitada a las organizaciones de usuarios de sistemas de agua de gestión colectiva en una relación subordinada al Estado, ante quien están obligados a cumplir con múltiples requisitos, condiciones, planes de mejora, etc., si es que quieren continuar existiendo o conservar los derechos de agua otorgados por el Estado.

En el marco legal de las aguas del decenio de la «Revolución Ciudadana», la capacidad de las organizaciones de gestión colectiva del agua para garantizar un servicio de calidad queda bajo sospecha. La aplicación del derecho humano al agua, que está bajo responsabilidad de las juntas administradoras del agua potable, según el artículo 40 del reglamento a la ley, deberá viabilizarse a través de un «plan de implementación» para cuya ejecución deberá contar con la tutela municipal.

Por otro lado, «los criterios de calidad para la prestación del servicio por parte de las juntas administradoras de agua potable» serán establecidos por la $\mathrm{ARCA}^{23}$. Exactamente lo mismo se prescribe para las organizaciones de regantes ${ }^{24}$. La

23 Artículo 47 del reglamento.

24 Artículo 51 del reglamento. 
ARCA tiene, además, la facultad de «comprobar la adecuación de los servicios a dichas regulaciones».

Hay, además, en la nueva legislación de aguas, una perspectiva homogeneizadora a la que quedan sometidas las organizaciones que gestionan colectivamente el agua. Esto queda claro cuando la ley, en sus artículos 43 y subsiguientes, al hacer referencia a la gestión comunitaria - y en general colectiva- del agua, se refiere exclusivamente a la forma «juntas de agua». Es más, el artículo 45 establece que la prestación de los servicios comunitarios de agua «se realizará exclusivamente a través de juntas de agua potable-saneamiento y juntas de riego, las mismas que deberán inscribirse en el registro público del agua».

Dentro de esa misma lógica, no obstante que el artículo 54 de la ley reconoce que «los sistemas comunitarios podrán gestionar de forma integrada los servicios de abastecimiento de agua de consumo humano y riego en aquellas áreas en las cuales resulte aconsejable», el énfasis de la ley es que se diferencie la gestión colectiva del abastecimiento de agua para consumo de la gestión colectiva del riego. Con ello, de espaldas a la realidad en gran parte de las zonas rurales del país en donde - y como es absolutamente lógico — una misma organización suele responsabilizarse de la gestión del agua para riego, consumo poblacional y en muchas ocasiones incluso para abrevadero de animales, en la normativa oficial se insiste en la idea de fragmentar la gestión territorial — «integral e integrada»-del agua.

Por último, en cuanto al tratamiento que la ley da a las organizaciones que gestionan colectivamente sistemas de agua de consumo doméstico en comunidades rurales o barrios periurbanos, su alcance territorial queda limitado a aquellas zonas en las cuales el abastecimiento de agua quede fuera de las posibilidades de los municipios ${ }^{25}$.

\section{¿Prácticas tradicionales de manejo del agua o reconocimiento del derecho consuetudinario en la gestión de las aguas?}

Distanciándose de las disposiciones constitucionales sobre derechos colectivos de comunas, comunidades, pueblos y nacionalidades indígenas, la ley no hace referencia al derecho consuetudinario de esas colectividades respecto de la gestión y uso del agua.

25 Tal es la orientación desarrollada en los artículos 43 y 46 de la ley. 
Ciertamente la ley formaliza una serie de derechos de participación de comunas, comunidades, pueblos y nacionalidades indígenas, pero tal noción está desarrollada como formalidad declarativa, como mecanismo de legitimación social de la política estatal y como responsabilidad que las colectividades indígenas deben compartir con el Estado ${ }^{26}$.

La ley formaliza una visión excluyente de construcción de las políticas en relación con la gestión del agua. Un claro ejemplo de lo señalado se refleja en la redacción del artículo 72 :

Artículo 72.- Participación en la conservación del agua. Las comunas, comunidades, pueblos y nacionalidades tienen el derecho a que el Estado, a través de sus instituciones, articule políticas y programas para la conservación, protección y preservación del agua que fluye por sus tierras y territorios.

El ejercicio de este derecho no prevalecerá ni supondrá menoscabo alguno de las atribuciones que sobre el agua le corresponde al Estado.

De la lectura del artículo no se puede desprender otra conclusión que el derecho al que hace referencia, en suma, no ha sido de las colectividades indígenas, sino del Estado.

Desconociendo también todo lo que en América Latina se ha debatido y construido teóricamente en torno a la noción de «pluralismo jurídico», que implica el reconocimiento del derecho consuetudinario de los pueblos de origen ancestral como un sistema jurídico con niveles de autonomía, en la ley apenas se hace referencia a las «prácticas tradicionales» (artículos 52, 53, 74), y en el mejor de los casos, a las «formas colectivas y tradicionales de manejo del agua» (artículo 48), cuya aplicación «está garantizada» siempre y cuando estén registradas ante la Senagua (artículos 48 y 74$)^{27}$.

En el artículo 75 de la ley, eludiendo cualquier referencia al derecho consuetudinario, se hace referencia a «los órdenes consuetudinarios».

En general, la ley reduce la gestión comunitaria de las colectividades ancestrales a:

\footnotetext{
26 Véanse los artículos 71 y subsiguientes de la ley.

27 Incluso al inicio, en el reglamento a la ley, en el artículo 52 se estableció que la falta de inscripción de las «prácticas consuetudinarias» en el registro público del agua determinará que no pueda considerarse como tal «la que en teoría, podría haber existido en las colectividades nombradas». Una reforma al reglamento en este artículo atenuó su contenido, quedando establecido que «dicho registro se efectuará únicamente para efectos declarativos».
} 
[...] la participación en la protección del agua y en la administración, operación y mantenimiento de la infraestructura de la que se beneficien los miembros de un sistema de agua y que no se encuentre bajo administración del Estado (artículo 32).

De esta manera, la legislación de aguas, la que más razones tenía para incorporar una perspectiva de pluralismo jurídico, termina no solo siendo un lamentable ejemplo de monismo jurídico sino además un ejemplo de grosera confusión en torno a la naturaleza del derecho consuetudinario ${ }^{28}$.

\section{ELEMENTOS DE DISCUSIÓN}

Se propone organizar la discusión a partir de las «racionalidades» (práctica, jurídica y política), así como desde los «discursos» (deóntico e ideológico) que contiene la LORHUAA.

¿A qué razón práctica y razón de consistencia (García Amado) responde la Ley de Recursos Hídricos del Ecuador? ¿A qué reglas de la argumentación racional (Habermas) responde dicha ley? ¿A la de la construcción de una sociedad más democrática o a la afirmación de un modelo de control vertical y excluyente del manejo y aprovechamiento del agua?

La insistencia de la ley en asegurar para el Estado el control absoluto en la planificación y gestión del recurso hídrico y un rol de interventor cuando la gestión comunitaria del agua sea considerada — por el mismo Estado — como ineficiente; la perspectiva homogeneizadora a la que quedan sometidas las organizaciones que gestionan colectivamente el agua; la desnaturalización de los mandatos y lineamientos constitucionales en lo referente a la participación social; el desconocimiento del derecho consuetudinario en la gestión comunitaria del agua $-\mathrm{y}$ en contrapartida el reclamo de la ley por una gestión basada en la «eficiencia técnica»— no parecen precisamente contribuciones de la ley a la construcción de una sociedad democrática e incluyente, que reconoce y valora su diversidad.

El desdén por las experiencias comunitarias en torno al agua, así como por las alianzas público-comunitarias para la gestión del agua, tiene en la ley como

28 Cualquier diccionario jurídico elemental va resaltar la diferencia entre el derecho positivo, como expresión de la capacidad legislativa de los Estados, cuya normatividad para tener vigencia requiere de su publicación oficial o inscripción en registros públicos, a diferencia del derecho consuetudinario, que expresa la capacidad de autorregulación, de concebir y aplicar el derecho y la justica que, desde su particular cosmovisión, tienen los grupos humanos de raigambre histórica e identidad cultural, derecho este de tradición fundamentalmente oral. 
contrapartida la falta de regulaciones claras que permitan revertir la histórica tendencia del acaparamiento de las aguas para la irrigación en la producción agrícola y agroindustrial.

El ya citado García Amado nos recuerda que «no toda legislación acontecida en democracia será, pues, igualmente racional, sino que habrá que establecer las condiciones del modo de legislar acordes con las exigencias prácticas de la democracia» (2003, p. 17).

\section{CONCLUSIONES}

Los elementos revisados parecen dejar en claro que la definición de los contenidos que dieron forma al texto oficializado de la Ley de Recursos Hídricos estuvo lejos de cualquier apego a las reglas de la argumentación racional o de la razón práctica. Si hay alguna racionalidad en la ley, no es otra que la racionalidad misma del poder.

A modo de hipótesis, se puede dejar planteado que la lógica de quienes formularon los contenidos del cuerpo normativo objeto de este análisis se orientó por criterios como los siguientes:

a) El intento por conciliar dos agendas políticas: la agenda recogida en la Constitución de 2008 y la agenda modernizadora de la «Revolución Ciudadana», que se expresa en la construcción discursiva de «cambio de la matriz productiva y energética». Mientras la agenda constitucional fue delineando los principios, enunciados y normas de carácter general de la ley, la otra agenda fue definiendo varias de las regulaciones específicas de la ley, a la vez que dejó por fuera de su contenido diversos aspectos que formaban parte de las versiones previas, especialmente de la versión diecisiete, que - con todas limitaciones que tuvo-, fue la que mejor recogía las demandas sociales en torno al marco normativo de las aguas.

b) En un contexto marcado por una sostenida resistencia social - especialmente de los pueblos indígenas y comunidades rurales - a proyectos extractivistas y a megaproyectos cuya viabilidad se basa en el aprovechamiento del agua, en la afectación a sus cualidades o en ambas cosas a la vez (que es lo más común), el Estado debe asegurarse el control indiscutible del agua ante los financistas, constructores, concesionarios y grandes beneficiarios de la infraestructura hidráulica construida con recursos públicos, con lo cual asume la condición de garante de las lógicas 
rentistas de aprovechamiento del agua. Esta cuestión podría resumirse en una frase: «aguas públicas, para fines privados».

Por otro lado, analizada la ley como un conjunto de construcciones discursivas, resulta de interés constatar que, además de los discursos de sentido deóntico e ideológico, en la LORHUAA aparece con nitidez una tercera construcción discursiva, de sentido legitimador, no precisamente de la prevaleciente estructura de reparto social del agua — cuestión que es función del discurso de sentido ideológico-, sino una construcción discursiva legitimadora de la misma ley, es decir, de autolegitimación.

De hecho, hay una construcción discursiva autolegitimadora cuando, por ejemplo, en la ley se hace referencia a derechos y garantías, participación social, prohibición de privatización del agua, redistribución del agua, gestión integral e integrada de los recursos hídricos, etc., en tanto que son aspectos que por más de veinte años han estado presentes en las construcciones discursivas de las organizaciones sociales articuladas a la gestión del agua. Debe advertirse, sin embargo, que en la ley, tal construcción discursiva no tiene trascendencia prescriptiva o regulatoria.

En lo que hace referencia a la construcción discursiva de sentido deóntico habría que enfatizar que esta se orienta a garantizar la eficacia normativa de la ley, la que se centra en precisar el deber ser de las organizaciones sociales que gestionan colectivamente sistemas de agua, a través de prescripciones que establecen las más variadas exigencias, requisitos y condiciones que aquellas deben cumplir si no quieren naufragar en las aguas profundas del iuspositivismo de la «Revolución Ciudadana».

Del discurso de sentido ideológico, habría que destacar una construcción que expresa una ideología corporativista de un Estado que a través de la ley, quiere garantizarse un control vertical de las aguas y su gestión, para lo cual, desde un monismo jurídico históricamente desfasado, muy próximo a la Escuela de la Exégesis del siglo XIX, exalta las nociones de lo técnico, lo eficiente, etc., asumiendo que tales nociones solo pueden situarse desde el Estado.

Por otra parte, es claro que la ley reproduce una ideología de herencia colonial que desconoce y desprecia las capacidades y saberes populares, campesinos e indígenas que se despliegan desde una multiplicidad de prácticas y formas organizativas en los sistemas de gestión colectiva del agua.

Finalmente, y a propósito de las construcciones discursivas que dieron su forma final a la Ley de Recursos Hídricos, parafraseando a Andrés Guerrero, uno 
de los más destacados pensadores ecuatorianos contemporáneos, solo faltaría por añadir que, como buena parte de la legislación configurada y reconfigurada en el último decenio, la Ley de Recursos Hídricos refleja con nitidez la semántica de la dominación ${ }^{29}$.

\section{REFERENCIAS BIBLIOGRÁFICAS}

Arvizu, Carmen. Conflictos normativos: las antinomias en el sistema jurídico mexicano. Su ubicación en la formación del abogado. Departamento de Derecho, UNISON. Recuperado el 2 de febrero de 2016 de http://www.juridicaformativa. uson.mx/memorias/iv_coloquio/doc/MesaJuridicoFormativa/CarmenHortenciaArvizuI.pdf

Asamblea Nacional (2014). Ley Orgánica de Recursos Hídricos, Usos y Aprovechamiento del Agua. Registro Oficial 305. Segundo suplemento.

Asamblea Nacional Constituyente (2008). Constitución del Ecuador. Montecristi.

Atienza, Manuel (2005). Las razones del derecho. Teorías de la argumentación jurídica. Instituto de Investigaciones Jurídicas. Serie Doctrina Jurídica, 134. Universidad Autónoma de México. https://doi.org/10.14198/doxa2007.30.55

Correas, Óscar (2010). Crítica de la ideología jurídica. Ensayo sociosemiológico. México D.F.: Coyoacán.

Correas, Óscar (2010[2004]). Teoría del Derecho. Colección Argumentos. México D. F.: Fontamara.

Dourojeanni, Axel (2010). «Lineamientos para orientar la aplicación de la Ley de Recursos Hídricos del Ecuador. La gestión integrada de recursos hídricos por cuenca hidrográfica». Documento de trabajo.

Foro de los Recursos Hídricos (varios años). Memorias de los encuentros nacionales. Consorcio CAMAREN. Quito (documentación disponible en: www.camaren. org).

García Amado, Juan A. (2003). Ensayos de Filosofia Jurídica. Bogotá: Temis.

Gaybor, Antonio (2008). «El despojo del agua y la necesidad de una transformación urgente». Foro de los Recursos Hídricos. Quito.

Gobierno de la República del Ecuador (2015). Decreto ejecutivo 650. Reglamento a la Ley Orgánica de Recursos Hídricos, Usos y Aprovechamiento del Agua.

29 Un trabajo de Andrés Guerrero (1991) lleva por título La semántica de la dominación: el concertaje de indios. 
Gobierno de la República del Ecuador (2015). Decreto ejecutivo 740. Reforma al Reglamento a la Ley Orgánica de Recursos Hídricos, Usos y Aprovechamiento del Agua.

Guerrero, Andrés (1991). La semántica de la dominación: el concertaje de indios. Quito: Libri Mundi.

Wittfogel, Karl A. [1963] (1966). Despotismo oriental. Estudio comparativo del poder totalitario. Madrid: Guadarrama.

Wolkmer, Antonio (2003). Introducción al pensamiento jurídico crítico. Colección en Clave del Sur. Bogotá: ILSA. 


\section{ANEXO 1}

\begin{tabular}{|c|c|}
\hline \multicolumn{2}{|r|}{ La participación social en la Ley de Recursos Hídricos } \\
\hline $\begin{array}{l}\text { Sentido a la parti- } \\
\text { cipación }\end{array}$ & Artículos \\
\hline $\begin{array}{l}\text { Como formalidad } \\
\text { declarativa }\end{array}$ & $\begin{array}{l}\text { Artículo 4.- Principios de la Ley. Esta Ley se fundamenta en los siguientes principios: } \\
\text { c) El Estado garantiza la gestión integral, integrada y participativa del agua. } \\
\text { Artículo } 35 \text {.- Principios de la gestión de los recursos hídricos. La gestión de los } \\
\text { recursos hídricos en todo el territorio nacional se realizará de conformidad con los } \\
\text { siguientes principios: } \\
\text { e) La participación social se realizará en los espacios establecidos en la presente } \\
\text { Ley y los demás cuerpos legales expedidos para el efecto. } \\
\text { Artículo 40.- Principios y objetivos para la gestión del riego y drenaje. El riego y drenaje } \\
\text { es un medio para impulsar el buen vivir o sumak kawsay. La gestión del riego y drenaje } \\
\text { se regirán por los principios de redistribución, participación, equidad y solidaridad, } \\
\text { con responsabilidad ambiental. } \\
\text { Artículo } 62 \text {.- Mujer y derecho humano al agua. Toda política en materia de agua } \\
\text { deberá incorporar la perspectiva de género de forma que se establezcan medidas con- } \\
\text { cretas para atender las necesidades específicas de la mujer en el ejercicio del derecho } \\
\text { humano al agua. } \\
\text { Del mismo modo, se adoptarán medidas con el objeto de alcanzar la igualdad formal } \\
\text { y material entre mujeres y hombres especialmente en las actividades de participación } \\
\text { comunitaria sobre la gestión del agua, la obtención de la misma y el fortalecimiento } \\
\text { de las mujeres como actoras de cambio. }\end{array}$ \\
\hline $\begin{array}{l}\text { Como mecanismo } \\
\text { de legitimación de } \\
\text { las decisiones o } \\
\text { actuaciones esta- } \\
\text { tales }\end{array}$ & $\begin{array}{l}\text { Artículo 26.- Funciones del Consejo de Cuenca. Corresponde al Consejo de Cuenca } \\
\text { el ejercicio de las siguientes funciones: } \\
\text { 5. Participar en los procesos de consulta que realice la Autoridad Única del Agua y } \\
\text { proponer temas prioritarios para la gestión de la cuenca o de las unidades hídricas } \\
\text { que la conforman; } \\
\text { Artículo 30. Elaboración de los planes de recursos hídricos. El Plan Nacional de Recur- } \\
\text { sos Hídricos y los planes de gestión integral por cuenca hidrográfica serán formulados } \\
\text { por la Autoridad Única del Agua. El Consejo Intercultural y Plurinacional del Agua y } \\
\text { los consejos de cuenca participarán en la formulación de sus directrices. } \\
\text { El Plan Nacional de Recursos Hídricos, una vez formulado, será puesto a considera- } \\
\text { ción del Consejo Intercultural y Plurinacional del Agua. Los planes de gestión integral } \\
\text { por cuenca hidrográfica, una vez formulados, serán sometidos a conocimiento de los } \\
\text { consejos de cuenca respectivos, luego de lo cual serán aprobados por la Autoridad } \\
\text { Única del Agua. }\end{array}$ \\
\hline $\begin{array}{l}\text { Como homo- } \\
1 \text { ogación de } \\
\text { responsabilidad } \\
\text { compartida con el } \\
\text { Estado }\end{array}$ & $\begin{array}{l}\text { Artículo 12.- Protección, recuperación y conservación de fuentes. El Estado, los } \\
\text { sistemas comunitarios, juntas de agua potable y juntas de riego, los consumidores } \\
\text { y usuarios, son corresponsables en la protección, recuperación y conservación de } \\
\text { las fuentes de agua y del manejo de páramos así como la participación en el uso y } \\
\text { administración de las fuentes de aguas que se hallen en sus tierras, sin perjuicio de las } \\
\text { competencias generales de la Autoridad Única del Agua de acuerdo con lo previsto en } \\
\text { la Constitución y en esta Ley. (...) } \\
\text { Artículo 44.- Deberes y atribuciones de las juntas administradoras de agua potable. } \\
\text { Constituyen deberes y atribuciones de las juntas administradoras de agua potable } \\
\text { comunitarias, los siguientes: } \\
\text { 4. Participar con la Autoridad Única del Agua en la protección de las fuentes de } \\
\text { abastecimiento del sistema de agua potable, evitando su contaminación; }\end{array}$ \\
\hline
\end{tabular}

